\title{
eftul Study on the Fluidisation Behaviour of Geldart C Glass Powders
}

\author{
K.Saleh ${ }^{1}$, X.B.Cami, A.Thomas, P.Guigon \\ Chemical Engineering Department, \\ CNRS-UMR 6067, Compiegne University of \\ Technology*
}

\begin{abstract}
The main objective of this work was the study of the fluidisation behaviour of a glass powder in order to allow its application by electrostatic pulverisation. The high density and the small diameter of the original product lead to bed channelling and slugging. To avoid these inconsistency problems, different fluidisation-aid techniques were experimented with: incorporation of easy-to-fluidise large spherical glass particles into the glass powder, the use of mechanical agitation and the addition of four different types of flow conditioners (or glidants). Four batches containing $1 w / w \%$ of different fluidisation additives (two containing hydrophilic additives and two hydrophobic additives) were tested. Fluidisation additives were Aerosils ${ }^{\circledR}$, which are nano-sized silica products. The quality of fluidisation was determined by monitoring the pressure drop through the bed during fluidisation experiments at decreasing air velocities.

Two sizes of spherical glass particles were used as easy-to-fluidise particles. Nevertheless, the fluidisation was not obtained by means of this technique. Using the stirring system, a better but still poor fluidisation was achieved, although its quality was improved by adding flow conditioners. An insignificant influence of the stirring speed on fluidisation was observed when using the fresh powder or batches containing hydrophilic fluidisation additives. Moreover, the influence of the proportion of additive was tested in six batches containing 0.1, 0.2, 0.3, 0.4, 0.5, and $1 \mathrm{w} / \mathrm{w} \%$ of the agent, which led to the most satisfactory improvement in fluidisation behaviour of the glass powder.
\end{abstract}

Keywords: Fluidisation, Fluidised bed, Glass powder, Flow conditioner, Agitation, Glidants

\section{Introduction}

One of industrial applications of fine glass powders is their electrostatic deposition on the surface of glass substrates such as sheets or decorative objects. Further heating of coated objects leads to subsequent sintering of the deposited layer of glass powder and formation of opaque patterns. However, dielectric properties of glass powders are inappropriate to their electrostatic application. Hence, the electrostatic deposition of glass powders requires their coating with suitable coating agents. The coating operation can be performed in a fluidised-bed coater (e.g. 1,2)), which

\footnotetext{
Accepted: August 14, 2006

BP 20259, 60205 Compiegne cedex, France

1 Corresponding Author

TEL: +33-344235274, Fax: +33-344231980

E-mail: khashayar.saleh@utc.fr
}

should ensure a homogeneous covering of particles. In this technique, the fluidisation behaviour of powders to be coated is fundamental and decisive for the feasibility and the quality of coating. The main objective of this work is to study the fluidisation behaviour of a Geldart C-class powder derived from the grinding of recycled glass bottles. It is well known that this type of powder has poor flowability as well as poor fluidisation properties.

According to Geldart's classification ${ }^{3)}$, fine powders could belong to two main groups with respect to their fluidisation behaviour: Group A particles that are considerably expanded before bubbling begins and Group $\mathrm{C}$ particles that are difficult or impossible to fluidise. This complexity is due to the interparticle forces that are greater than gravitational forces ${ }^{4)}$. In the absence of liquid bridges, adsorbed liquid layers and/or electrostatic forces, the most significant attractive interactions are van der Waals forces ${ }^{4)}$. Ac- 
cording to several investigations, interparticle forces play a key role on fluidisation behaviour of fine powWders. For example, Lauga et al. ${ }^{5)}$ showed that there is a direct relationship between the expansion of $\mathrm{Ni} / \mathrm{SiO}_{2}$ aerogels in a fluidised bed and the interparticle interactions resulting from van der Waals forces. In addition, valuable information about the role of interparticle forces in the fluidisation of fine powders (class C) can be found in recent review articles of Yang ${ }^{6)}$ and Seville et al. ${ }^{7}$. There are several methods to improve a fine fluidisation process of Geldart C particles: adding easy-to-fluidise particles, fluidisation additives, agitation, vibration, centrifugation, acoustic field, magnetic field, etc. Easy-to-fluidise particles are generally powders belonging to class B having a size between 100 and about $1000 \mu \mathrm{m}$. Addition of this type of product to class $\mathrm{C}$ powders improves the fluidisation due to the mixing action of larger particles which can be assimilated to a mechanical agitator.

Another common solution to improve the fluidisation of very fine powders is the addition of small amounts of flow conditioners or glidants. This type of product is made up of submicron-size primary particles. Due to their small size, when adhered on the surface of core particles, primary particles behaves like a surface asperity. This leads to an increase in the minimum contact distance of two interacting particles, which in turn decreases the van der Waals forces $^{8,9)}$. Silica-, alumina- and carbon-based glidants are the most widely used flow conditioners.

In this work, the effect of the addition of both easyto-fluidise particles and flow conditioners as well as the use of agitation systems on the fluidisation behaviour of glass powders was studied.

The objective was to identify the optimal operating conditions for the fluidisation of glass powders allowing their further coating as well as a better understanding of the action mechanisms of glidants.

\section{Definition of Fluidisation Criteria and Their Interpretation}

A gas passing through a bed of powder exerts a friction force on particles that increases with the gas velocity. This results in a pressure drop between the entry and exit points of the bed. As illustrated in Fig. 1 , a progressive increase of the pressure drop can be observed with increasing superficial gas velocity. Regarding the superficial gas velocity, $U$, two regimes can be distinguished: a fixed-bed region where pressure drop varies directly with the gas velocity, and a fluidised-bed zone where the pressure drop remains

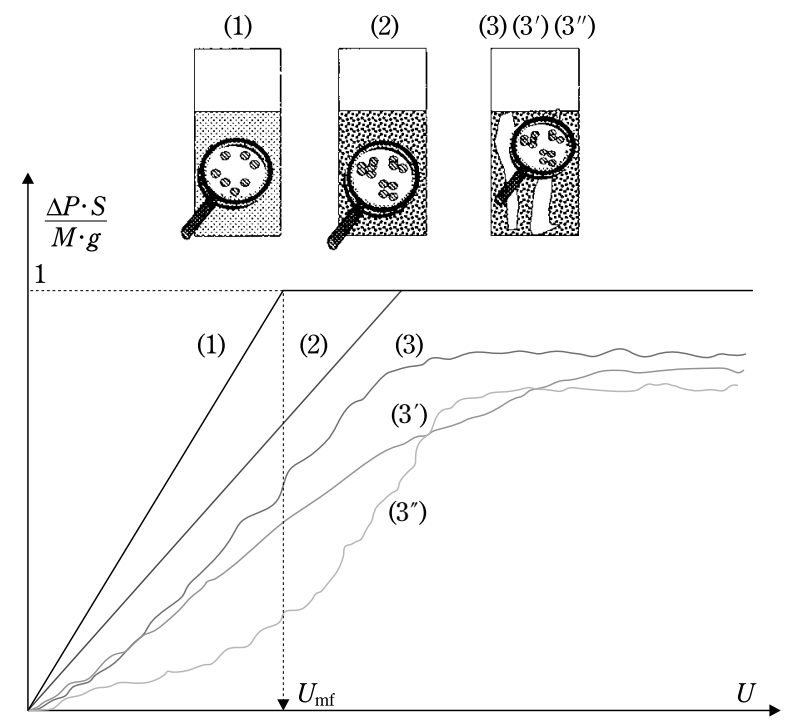

Fig. 1 Pressure drop profile (1. Homogeneous fluidisation of particles, 2. Homogeneous fluidisation of agglomerates, 3, 3', 3". Channelling and slugging fluidisation).

constant. The transition velocity between these two regimes is known as minimal fluidisation velocity, $U_{m f}$. Fig. 1 summarises the fluidisation trends of more or less cohesive powders. For a perfect particulate fluidisation (i.e. each particle is individually suspended independently of surrounding particles) and in the absence of particle elutriation, the total friction force exerted on the bed $(\triangle P \cdot S)$ is equal to the bed weight $(M \cdot g)$. In addition, for an ideal fluidisation, the minimal fluidisation velocity, $U_{m}$, can be determined by theoretical models or by semi-empirical correlations (e.g., Thonglimp ${ }^{10)}$ ). Note that these models do not take into account the interparticle forces. For more cohesive particles, the fluidisation takes place through the suspension of ephemeral agglomerates rather than individual particles. This phenomenon does not affect the total pressure drop but leads to an increase in experimentally measured values of $U_{m f, e x p}$. Finally, for more cohesive particles, slugging and channelling of the bed might occur. This leads to higher values of $U_{m f \text { fexp }}$, on the one hand, and to lower pressure drops on the other hand because the effective gas-particle contact area is reduced.

Accordingly, in addition to the minimal fluidisation velocity $U_{m}$, the following criteria could be used to characterise the fluidisation behaviour of fine particles:

- Fluidisation index, $F I$

This parameter is the ratio of the minimum fluidisation velocity determined by a semi-empirical cor- 
relation valid for ideal fluidisation and the minimum flotidisation velocity experimentally determined:

$$
F I=\frac{U_{m f, c o r r}}{U_{m f, e x p}}
$$

Obviously, FI depends on the empirical correlation used to calculate the minimum fluidisation velocity $\left(U_{m f, c o r r}\right) . F I$ is equal to unity for easy-to-fluidise particles $(>100-200 \mu \mathrm{m})$ and tends towards zero for impossible-to-fluidise powders.

- Fluidisation quality, $F Q$

Fluidisation quality is defined as the dimensionless pressure drop through the bed:

$$
F Q=\frac{\Delta P \cdot S}{M \cdot g}
$$

An $F Q$ equal to unity characterises a homogeneous fluidisation of either individual particles or ephemeral agglomerates. In contrast, channelling and slugging phenomena lead to poorer fluidisation qualities.

\section{- Dynamic diameter of agglomerates, $d_{a}$}

This parameter is an indication of the equivalent size of ephemeral agglomerates. $d_{a}$ is a hypothetical diameter which allows matching predicted and experimentally measured values of $U_{m}$, i.e. the agglomerate mean size necessary to have an $F I$ equal to unity. $d_{a}$ can be easily calculated once an adequate correlation is chosen.

Note that the ratio between the equivalent diameter of dynamic agglomerates and the elementary particles' mean size $\left(d_{a} / d_{p}\right)$ is a rough and qualitative measure of interparticle cohesive forces: the more cohesive the powder is, the higher is the deviation of the ratio $d_{a} / d_{p}$ from the unity. In fact, one might consider that $d_{a}$ is the size of agglomerates which permits the interparticle forces to just be counterbalanced by break-up forces.

In this study, the semi-empirical correlation proposed by Thonglimp et $a l^{10)}$ was used for prediction of $U_{m f, c o r}$ :

$$
\frac{\rho_{p} U_{m f} d_{p}}{\mu}=\sqrt{31.6^{2}+0.0425 \cdot \frac{\rho_{g}\left(\rho_{p}-\rho_{g}\right) g d^{3}{ }_{p}}{\mu^{2}}}-0.0425
$$

Preliminary experiments conducted with perfectly fluidisable model glass beads showed that this correlation expects good $U_{m f, e x p}$ values.

Generally, knowing the fluidisation criteria, one can roughly classify the fluidisation behaviour of cohesive powders as indicated in Table 1.
Table 1 Classification of behaviour of powders according to fluidisation criteria

\begin{tabular}{c|c|c}
\hline FI & FQ & State \\
\hline $0.8-1$ & $0.7-1$ & $\begin{array}{r}\text { Homogeneous fluidisation of } \\
\text { particles }\end{array}$ \\
\hline$<<1$ & $0.8-1$ & $\begin{array}{c}\text { Homogeneous fluidisation of } \\
\text { agglomerates }\end{array}$ \\
\hline Very low & $0.6-0.8$ & Non-homogeneous fluidisation \\
\hline
\end{tabular}

\section{Experimental}

\subsection{Materials}

A glass powder (GP) with a median mean diameter of $2.65 \mu \mathrm{m}$ and a true density of $3100 \mathrm{~kg} / \mathrm{m}^{3}$ was used in this study. These parameters were measured using a Malvern Mastersizer analyser and a Helium pycnometer (Micromeretics, Accupyc 1330), respectively. The glass powder was prepared by milling recycled glass bottles. The higher density of this product with respect to the pure glass is due to impurities, in particular the presence of zinc oxide. The powder is cohesive, belonging to group $\mathrm{C}$ of Geldart's classification, which is characterised by a difficult fluidisation.

Two batches of easy-to-fluidise particles (EFP) were used. They were spherical glass beads with median mean diameters of 300 and $400 \mu \mathrm{m}$, respectively $\left(\rho=2650 \mathrm{~kg} \cdot \mathrm{m}^{3}\right)$. Both batches belong to Geldart's group B and fluidise easily with bubbling starting at minimum fluidisation velocity.

As for flow conditioners, four different types of Aerosils $^{\circledR}$ were used (Table 2). Aerosils ${ }^{\circledR}$ are made up of nano-size primary silica particles which are connected by solid bridges and which form nondispersive clusters having a size several times greater than that of primary particles (Fig. 2-a). Due to their small size, the clusters in turn form secondary aggregates of a few micrometres, which can easily be fragmented and dispersed.

In this study, the size distribution of non-dispersive aggregates was measured using a Zetasizer from Malvern Instruments. Several liquid dispersants were tested but the most effective was found to be Ethanol. Fig. 2-b represents a typical curve of non-dispersive clusters size distribution. The mean sizes calculated from measured size distributions are reported in Table 2 . As can be seen from data presented in this table, additives used here differ in the size of their primary particles and in their hydrophobe/hydrophile properties. Aerosil ${ }^{\circledR} 130$ and Aerosil ${ }^{\circledR} 200$ are both of hydrophilic nature but differ in the diameters of both 
$100 \mathrm{~nm}$

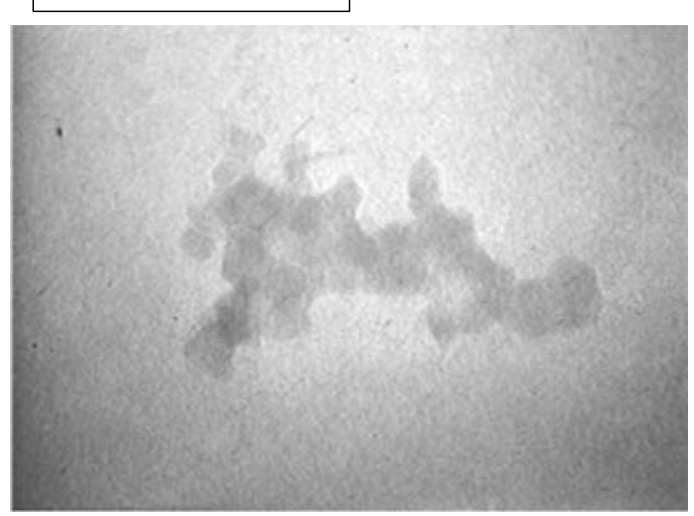

a) TEM image of an aggregate

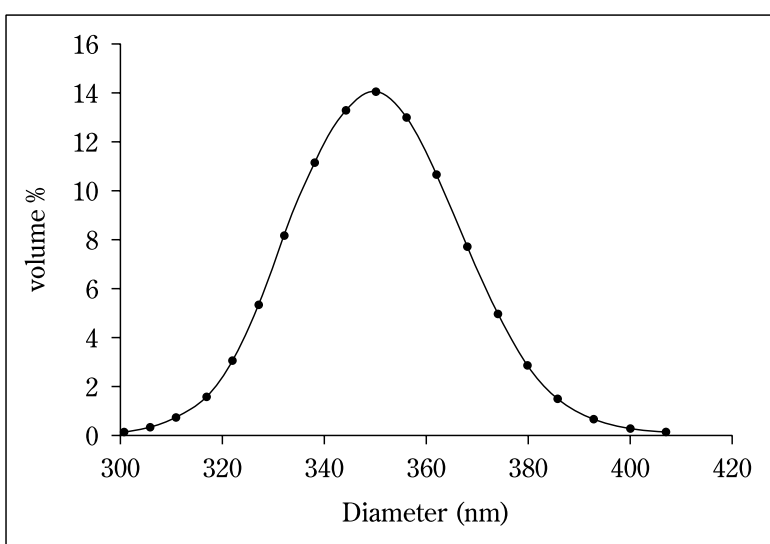

b) aggregate size distribution determined by PCS

Fig. 2 Size of non-dispersive aggregates (Aerosil ${ }^{\circledR} 812 S$ ).

Table 2 Fumed silica physico-chemical properties

\begin{tabular}{|c|c|c|c|c|c|c|}
\hline Aerosil $^{\circledR}$ & $\begin{array}{c}\text { Primary } \\
\text { particle size }^{\text {a }}\end{array}$ & $\begin{array}{c}\text { Aggregate } \\
\text { average size }^{b}\end{array}$ & $\begin{array}{c}\text { BET } \\
\text { Surface }^{a}\end{array}$ & $\begin{array}{c}\text { Tapped } \\
\text { density }^{\text {a }}\end{array}$ & $\begin{array}{l}\text { Carbon } \\
\text { content }\end{array}$ & $\begin{array}{c}\text { Methanol } \\
\text { wettability }^{\text {a }}\end{array}$ \\
\hline 130 & $16 \mathrm{~nm}$ & 320 & 130 & $50 \mathrm{~g} / \mathrm{L}$ & - & - \\
\hline 200 & $12 \mathrm{~nm}$ & 250 & 200 & $50 \mathrm{~g} / \mathrm{L}$ & - & - \\
\hline R972 & $16 \mathrm{~nm}$ & 350 & 110 & $50 \mathrm{~g} / \mathrm{L}$ & $0.6-1.2 \%$ & $30 \%$ \\
\hline R812S & $12 \mathrm{~nm}$ & 270 & 220 & $50 \mathrm{~g} / \mathrm{L}$ & $3-4 \%$ & $60 \%$ \\
\hline
\end{tabular}

a supplier's specifications

b aggregate size determined by PCS

primary particles and non-dispersive aggregates. Aerosil $^{\circledR}$ R 972 and Aerosil ${ }^{\circledR}$ R 812 S can be considered as hydrophobic homologous of Aerosil ${ }^{\circledR} 130$ and Aerosil $^{\circledR} 200$, respectively. Indeed, these agents have sizes of primary and non-dispersive particles that are similar to those of Aerosil ${ }^{\circledR} 130$ and 200, respectively, but their surface is treated by hydrophobic reagents, which are stable against hydrolysis.

\subsection{Preparation of powders}

A similar procedure was used to prepare both easyto-fluidise and glidant-added mixtures. Each powder mixture was prepared using a Pro-C-epT ${ }^{\circledR}$ Mi-Pro high shear mixer (maximum volume: $1.2 \cdot 10^{-3} \mathrm{~m}^{3}$ ). The mixing was performed for 1 hour at a rotational speed of $200 \mathrm{rpm}$. Preliminary experiments showed that these conditions permit achievement of an optimal effect of the flow additive.

\section{Easy-to-fluidise batches}

Several binary mixtures of fresh fine powder (GP) and coarse particles (EFP) were prepared with coarse particle concentrations of 10,20,30, 40 and 50 w/w\% (Table 3).

\section{Glidant-added batches}

Two series of glidant-added batches were prepared. In the first series, four batches were formulated each containing $1 \% \mathrm{w} / \mathrm{w}$ of different glidants. In the second series of batch formulation, five additional batches were prepared using Aerosil ${ }^{\circledR} \mathrm{R} 812 \mathrm{~S}$ with different percentages: $0.1,0.2,0.3,0.4$ and $0.5 \%$. This allows us to study the influence of additive percentage on fluidisation ability.

SEM micrographs presented in Fig. $\mathbf{3}$ show a view of additive-free and glidant-added glass powders. It can be observed that the glass powder has an irregular shape and a wide size distribution. Agglomerates of powder are also observed. These characteristics reinforce poor fluidisation ability.

\subsection{Experimental apparatus}

In order to characterise the fluidisation behaviour of the prepared powder batches, home-made fluidisation equipment was used. This apparatus consists of a conventional fluidised column properly instrumented to monitor the operating conditions as well as the bed level and the pressure drop through the bed. The apparatus includes three main parts: the fluidisa- 
a par ip

Table znsumpary of experiments and fluidisation criteria

\begin{tabular}{|c|c|c|c|c|c|c|c|c|}
\hline $\begin{array}{c}\text { Experiment } \\
\text { number }\end{array}$ & $\begin{array}{c}\text { Added } \\
\text { (secondary) product }\end{array}$ & $\begin{array}{c}\text { Weight } \\
\text { percentage } \\
\text { of additive }\end{array}$ & $\begin{array}{l}\text { Bed mass } \\
\quad(\mathrm{kg})\end{array}$ & $\begin{array}{l}\text { Stirring } \\
\text { velocity } \\
(\mathrm{rpm})\end{array}$ & $U_{m f}(\mathrm{~mm} / \mathrm{s})$ & $F I\left(\times 10^{4}\right)$ & $F Q$ & $d_{a}(\mu \mathrm{m})$ \\
\hline 1 & - & - & 1.0 & - & - & - & - & - \\
\hline 2 & - & - & 1.0 & 65 & 1.97 & 40 & 0.89 & 72 \\
\hline 3 & - & - & 1.0 & 110 & 1.97 & 40 & 0.94 & 71 \\
\hline 4 & - & - & 1.0 & 160 & 1.78 & 44 & 0.91 & 70 \\
\hline 5 & Glass beads $(300 \mu \mathrm{m})$ & $50 \%$ & 1.5 & - & - & - & - & - \\
\hline 6 & Glass beads $(400 \mu \mathrm{m})$ & $50 \%$ & 1.5 & - & - & - & - & - \\
\hline 7 & $\operatorname{Aerosil}^{\circledR} 130$ & 1 & 1.0 & - & - & - & - & - \\
\hline 8 & Aerosil $^{\circledR} 130$ & 1 & 1.0 & 65 & 0.90 & 87 & 0.94 & 48 \\
\hline 9 & Aerosil $^{\circledR} 200$ & 1 & 1.0 & - & - & - & - & - \\
\hline 10 & Aerosil $^{\circledR} 200$ & 1 & 1.0 & 50 & 0.62 & 117 & 0.98 & 39 \\
\hline 11 & Aerosil $^{\circledR} 200$ & 1 & 1.0 & 65 & 0.55 & 132 & 0.99 & 36 \\
\hline 12 & Aerosil $^{\circledR} 200$ & 1 & 1.0 & 80 & 0.64 & 113 & 0.99 & 41 \\
\hline 13 & Aerosil $^{\circledR}$ R972 & 1 & 1.0 & - & 3.27 & 24 & 0.93 & 95 \\
\hline 14 & Aerosil $^{\circledR}$ R972 & 1 & 1.0 & 65 & 0.86 & 91 & 0.97 & 49 \\
\hline 15 & Aerosil $^{\circledR}$ R812S & 0.1 & 0.9 & - & 3.37 & 23 & 0.89 & 100 \\
\hline 16 & Aerosil $^{\circledR}$ R812S & 0.2 & 0.9 & - & 3.43 & 23 & 0.88 & 102 \\
\hline 17 & Aerosil $^{\circledR}$ R812S & 0.3 & 0.9 & - & 2.26 & 35 & 0.89 & 83 \\
\hline 18 & Aerosil $^{\circledR}$ R812S & 0.4 & 0.9 & - & 2.18 & 36 & 0.88 & 81 \\
\hline 19 & Aerosil $^{\circledR}$ R812S & 0.5 & 1.0 & - & 2.06 & 38 & 0.95 & 75 \\
\hline 20 & Aerosil $^{\circledR}$ R812S & 1 & 1.0 & - & 2.13 & 37 & 0.96 & 75 \\
\hline
\end{tabular}

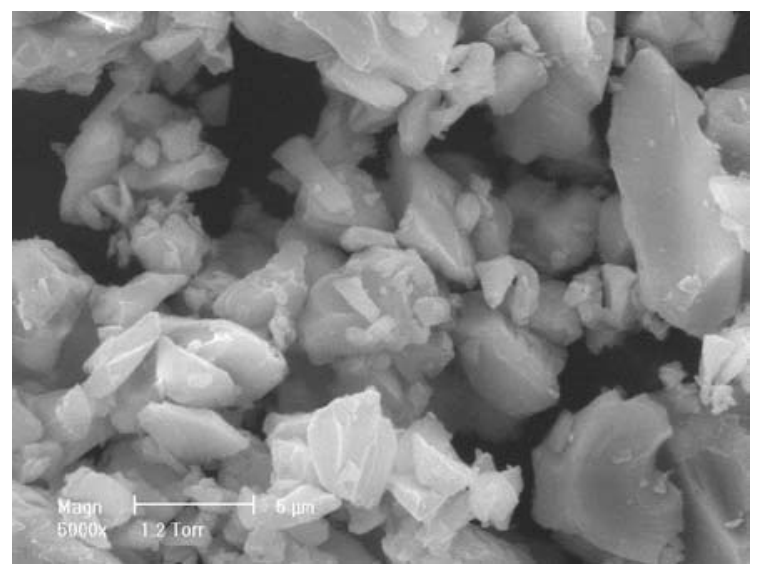

Fresh glass powder

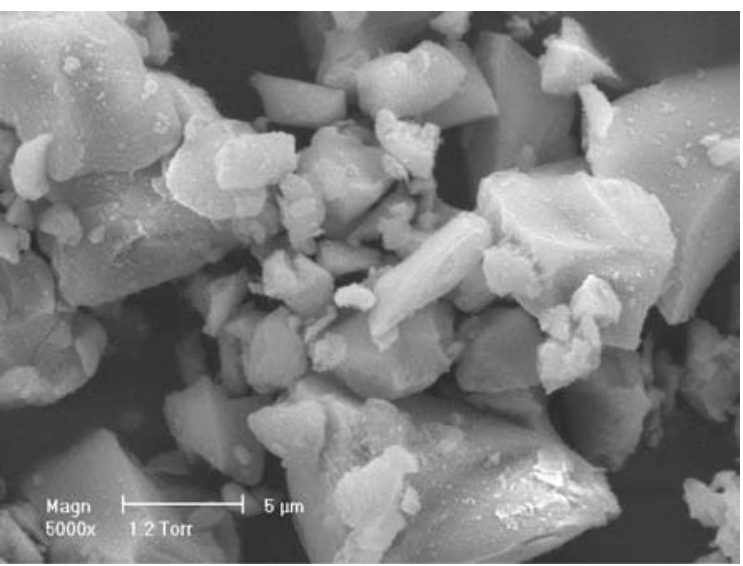

glass powder + Aerosil $^{\circledR} 200(1 \%$ w/w)

Fig. 3 SEM images of fresh and glidant-added particles.

tion column, the air flow circuit and the acquisition device. Fig. 4 shows a schematic diagram with some principal dimensions of the experimental set-up.

The fluidisation column is a Pyrex cylinder 100 $\mathrm{mm}$ in diameter and $500 \mathrm{~mm}$ in height. At the top of the column, an expanding freeboard section is mounted to permit minimisation of particle entrain- ment. The air stream exiting the freeboard section passes through a cyclone and elutriated particles are recovered. The air distributor is a metallic porous plate sandwiched between two filter papers. The distributor is placed between the fluidisation cylinder and the wind box, which is a $7.85 \cdot 10^{-3} \mathrm{~m}^{3}$ cylindrical chamber. Before entering the bed, the compressed 


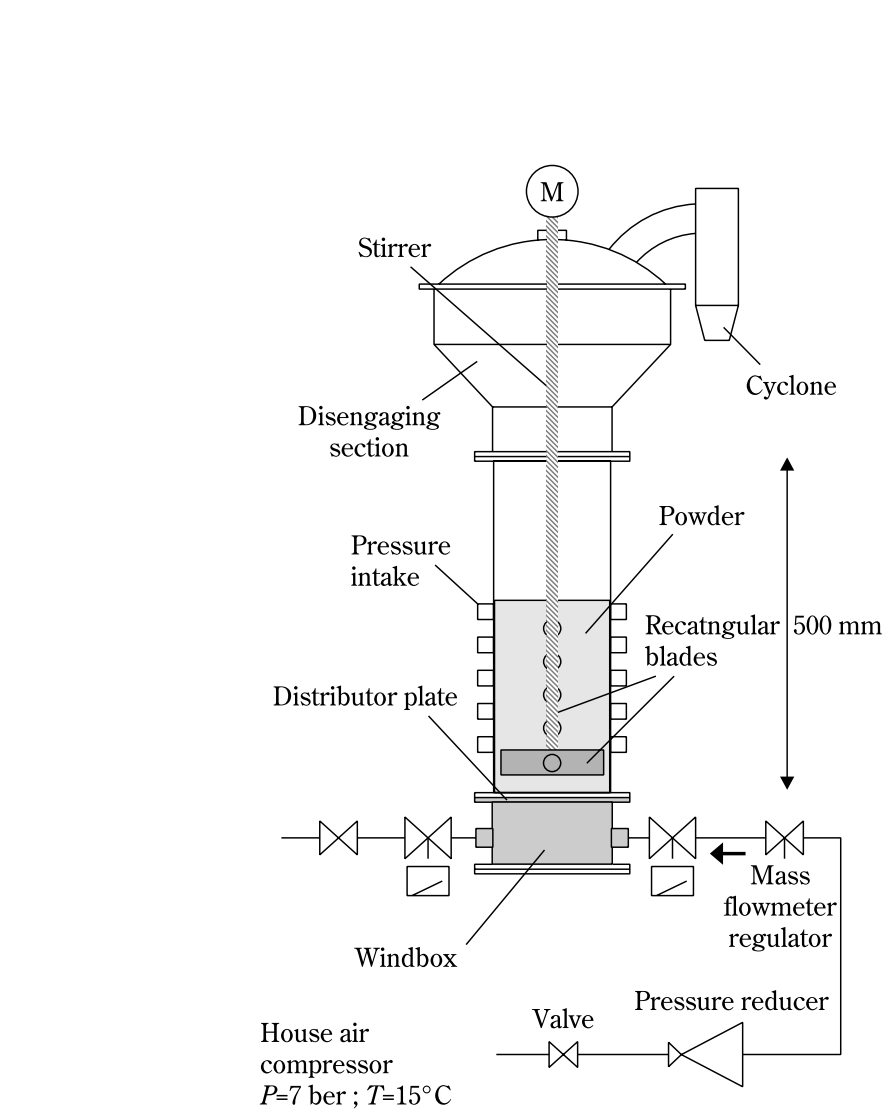

Fig. 4 Schematic diagram of experimental apparatus.

air passed through a filter, a pressure regulator and a mass flowmeter regulator. During each experiment, temperature and relative humidity inside the bed as well as pressure drops at different levels of the bed were monitored and recorded. Data acquisition was performed using a $\mathrm{HP} \mathrm{VEE}^{\circledR}$ program. The program permitted selection of all electro valves to ensure the desired air flow rates for the predefined time intervals. Consequently, once the bed is charged, fluidisation trials are automatically carried out without any operator intervention. More detailed information on the experimental apparatus and acquisition system can be found elsewhere ${ }^{11)}$.

In addition, an agitation system was used in some trials. This system was composed of a motor, a rotating shaft and an agitator mobile which is made up of two rectangular blade stirrers $(80 \times 15 \mathrm{~mm})$ placed at $20 \mathrm{~mm}$ from the air distributor.

\subsection{Fluidisation experiments}

The mass of each batch was fixed so that the condition $1.4<\mathrm{H} / \mathrm{D}<1.5$ was accomplished. Firstly, a determined initial mass of powder was introduced into the column in order to ensure a bed height of about 0.14-0.15 m. Prior to actual fluidisation tests, the bed was pre-conditioned to reduce the influence of initial bed packing . To this end, the air velocity was first increased and then decreased in steps of $0.11 \cdot \mathrm{min}^{-1}$ every $20 \mathrm{~s}$. After each pre-conditioning cycle, the bed height was checked. If the bed was too high (or too low) a corresponding amount of powder was added (or removed) and the pre-conditioning was repeated.

Fluidisation properties were determined at decreasing air velocities. Firstly, the gas velocity was fixed at its maximum value. Then the gas stream was decreased gradually and the pressure drop was measured at each step after having maintained a constant gas velocity during $60 \mathrm{~s}$ at least. Between each step, the gas velocity was increased to its maximum value for $60 \mathrm{~s}$. Each fluidisation test was repeated five times using exactly the same procedure. The reported values in this paper correspond to the mean value of all five runs. Note that the experimental values of minimum fluidisation velocity, $U_{m f, e x p}$, were determined by plotting $\Delta P$ vs. $U$ values in a log-log diagram as is recommended for fine powders of narrow size distribution (e.g. 12)). Such a presentation (not shown here) permits a better location of the transition point between the fixed state and fluidised bed.

\section{Results and Discussion}

Table 3 summarises the composition of all batches together with the operational conditions used during fluidisation experiments. As shown in this table, experiment no. ${ }^{\circ} 1$ corresponds to the glass powder with no additives or mechanical agitation. Experiments 2 to 4 aimed show the effect of agitation speed on the fluidisation of glass powder. The effect of incorporating easy-to-fluidise particles was studied in experiments 5 and 6 . Experiments 7 to 14 take into consideration the effect of the addition of $1 \% \mathrm{w} / \mathrm{w}$ of glidants, with or without agitation. Finally, experiments 15 to 20 emphasise the effect of the concentration of the glidant using Aerosil ${ }^{\circledR}$ R $812 \mathrm{~S}$.

The characteristic fluidisation curve of fresh glass powder (Fig. 5) shows that the product does not fluidise even at gas velocities much higher than $U_{m f, c o r}$ predicted by the correlation of Thonglimp et al (8 $\left.\times 10^{-6} \mathrm{~m} \cdot \mathrm{s}^{-1}\right)$. Not one fluidisation property can be determined for this powder as the fluidisation state could not be established. Hence, auxiliary means must be used to promote the fluidisation of the glass powder.

\subsection{Influence of agitation velocity}

The effect of mechanical agitation on the fluidisation behaviour of the glass powder is also presented in Fig. 5. These results show that mechanical agita- 


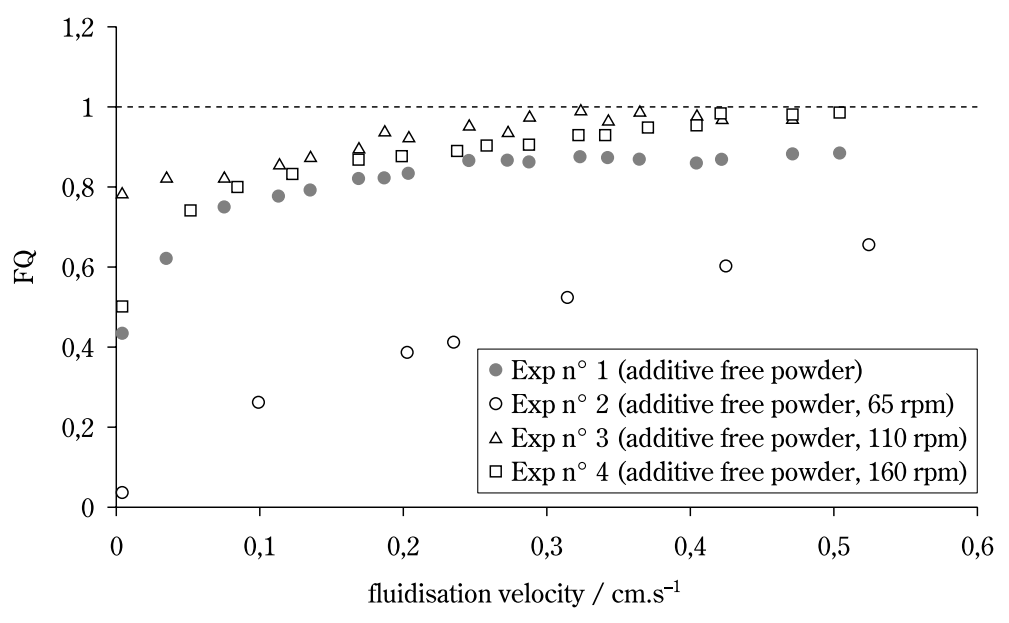

Fig. 5 Fluidisation curves for glass powder with and without mechanical agitation.

tion ensures a stable fluidisation operation with a relatively good quality. $F Q$ values at $65 \mathrm{rpm}$ range between 0.89 and 0.95 and are very close to unity at higher speeds. However, the fluidisation indexes are high $\left(40 \times 10^{-4}\right.$ to $\left.45 \times 10^{-4}\right)$. This indicates that fluidisation takes place through suspension of aggregates rather than individual particles. The dynamic diameter of aggregates is about $70 \mu \mathrm{m}$.

These results reveal the importance of mechanical agitation in the feasibility of operation. However, the intensity of agitation does not play a significant role on fluidisation properties. As can be seen from Fig. 5 and Table 3, an increase of rotational speed of agitation by a factor of 2 and 3 has no noticeable effect, neither on the quality of fluidisation nor on the fluidisation index, $F I$. This means that mechanical agitation improves the fluidisation by breaking up the channels and slugs and thereby ensuring a better distribution of the air stream within the bed. In contrast, mechanical agitation does not demolish dynamic aggregates. However, this observation might be modified if more shearing agitation systems are used (e.g. high shear blades).

\subsection{Influence of the addition of easy-to-fluidise particles}

Several batches containing easy-to-fluidise particles were used in this study. They differ in the mean size (300 and $400 \mu \mathrm{m})$ and the amount $(10,20,30,40,50 \%$ $\mathrm{w} / \mathrm{w})$ of the coarse population. We limit ourselves to present the results obtained with mixtures containing $50 \% \mathrm{w} / \mathrm{w}$ easy-to-fluidise particles (Table 3). Note that due to the presence of coarse particles, the dynamic diameter of aggregates has no meaningful significance for these experiments. The results showed that the fluidisation of glass powders is possible by the addition of coarse particles. However, $U_{m f, e x p}$ values were so high that great amounts of fine particles were elutriated. Although the $U_{m f, e x p}$ decreased when using smaller easy-to-fluidise particles, its value still remained too high to avoid this phenomenon. A partial remedy to this problem is to decrease the mean size of the coarse population. However, in our case, even the use of $100-\mu \mathrm{m}$ easy-to-fluidise particles did not ensure stable operation.

Another problem encountered with this technique is the segregation phenomenon, which appears at low gas velocities.

Consequently, compared to use of mechanical agitation, the addition of easy-to-fluidise particles does not seem to constitute a suitable technique for fluidisation of the glass powder used in this study. In fact, the operation lies between two undesired regimes, namely segregation and elutriation.

\subsection{Influence of the addition of flow condition- ers}

Fluidisation characteristic curves of powders containing $1 \% \mathrm{w} / \mathrm{w}$ of two types of hydrophilic flow conditioners are presented in Fig. 6. These results reveal that the introduction of hydrophilic additives does not improve the fluidisation properties of the original powder. The characteristic curves are quite similar for additive-free powders and mixtures containing hydrophilic glidants. Fluidisation is only possible with the use of mechanical agitation. In this case, $F Q$ values close to unity are obtained although FI remains low. For a given rotational speed, this enhancement is more pronounced for Aerosil ${ }^{\circledR} 200$. This can be attributed to the higher size of non-dispersive aggregates 


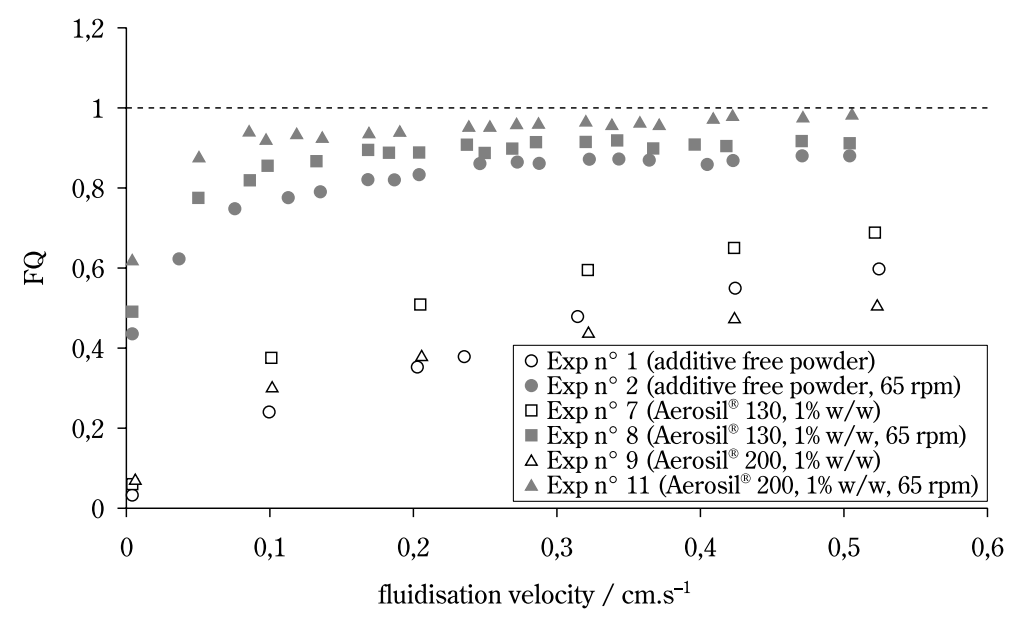

Fig. 6 Influence of adding hydrophilic additives with and without agitation.

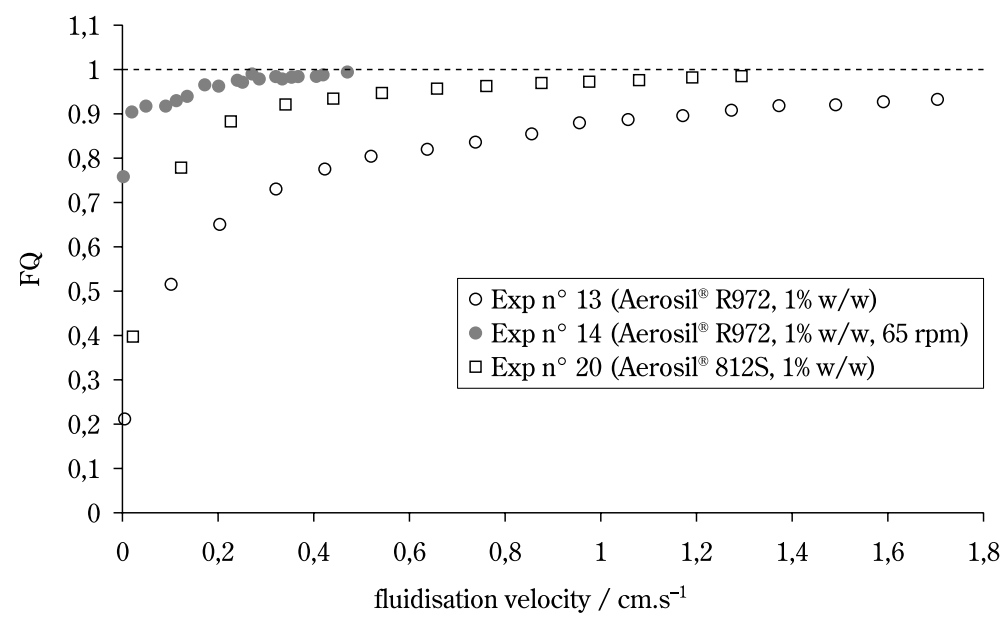

Fig. 7 Influence of adding hydrophobic additives.

for this additive compared to Aerosil ${ }^{\circledR} 130$ (Table 2). This might lead to a more effective "opening" effect between particles and hence a more pronounced reduction of van der Waals forces.

The results presented in Table 3 also confirm the observation made previously, i.e. the agitation rate (50, 65 and $80 \mathrm{rpm})$ has no influence on fluidisation properties.

The effects of the addition of hydrophobic agents on the fluidisation behaviour of the powder are presented in Fig. 7. These results confirm that the fluidisation enhancement in this case is largely better than that obtained by using hydrophilic agents. Using the agitation system and $1 \mathrm{w} / \mathrm{w} \%$ of hydrophobic glidants, fluidisation qualities higher than 0.9 are obtained (0.93 and 0.97 for Aerosil R972 and R812S , respectively) (Table 3).

Furthermore, it can be seen that glass powders containing these two types of additives can fluidise even without mechanical agitation. However, for Aerosil R972, fluidisation criteria indicate that agitation is still beneficial to operation and that fluidisation deteriorates when agitation is turned off. The difference between the effectiveness of these additives might be attributed to the size of non-dispersive aggregates on the one hand and the hydrophobicity extent of products on the other hand. In fact, according to manufacturer's specifications, Aerosil R812S is more hydrophobic than R972. Consequently, this product can be more easily dispersed over the hydrophilic surface of glass powder. Indeed, SEM images of the surface of glass powders (Fig. 8) corroborate this assumption and show that Aerosil R812S is more evenly distributed at the surface of host particles. In addition, Aerosil R812S is made up of larger nondispersive aggregates and is hence more suited to reducing interparticle forces.

Finally, it should be noted that a very marked ex- 


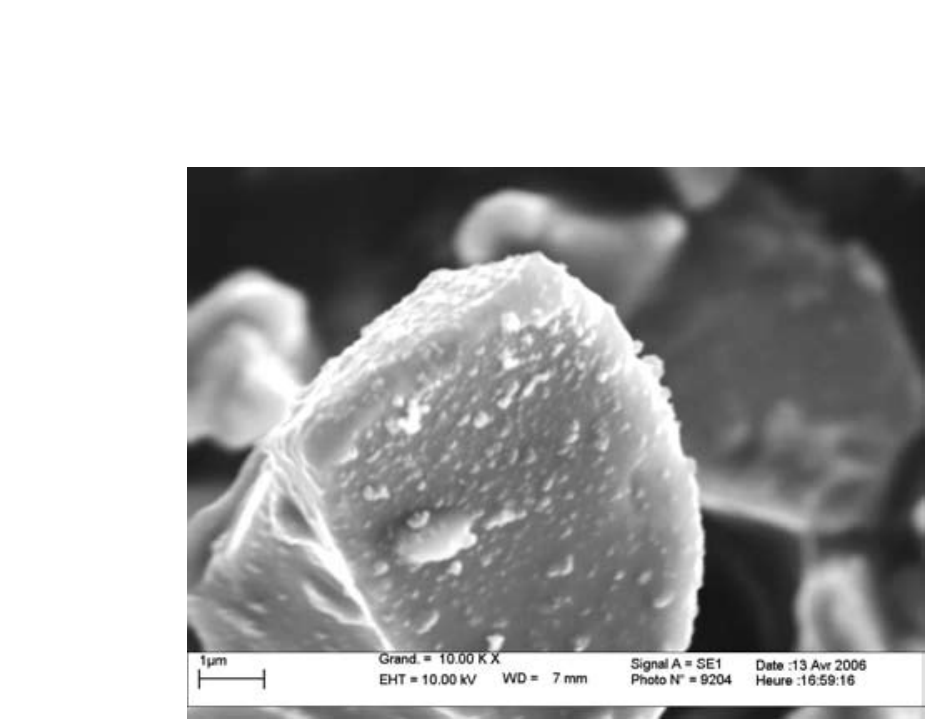

a) $\operatorname{Aerosil}^{\circledR} \mathrm{R} 972(1 \% \mathrm{w} / \mathrm{w})$

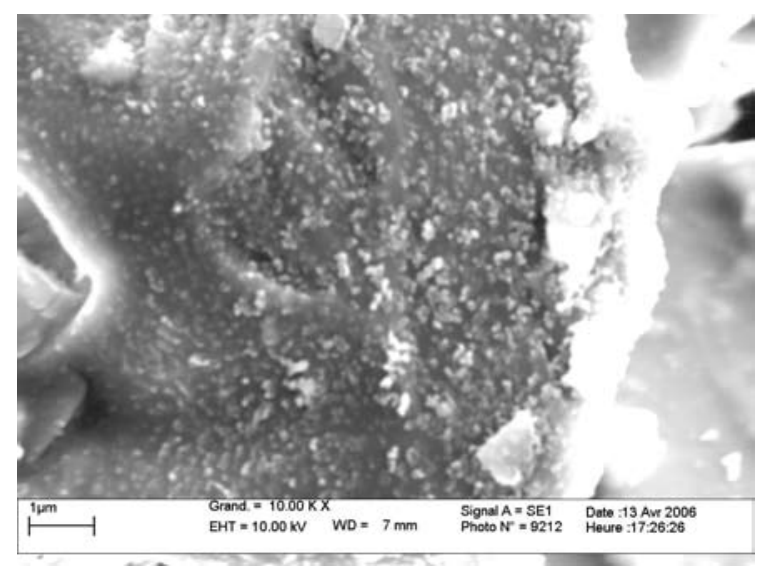

b) $\operatorname{Aerosil}^{\circledR} 812 \mathrm{~S}(1 \% \mathrm{w} / \mathrm{w})$

Fig. 8 SEM images of hydrophobic additives on the surface of glass particles.
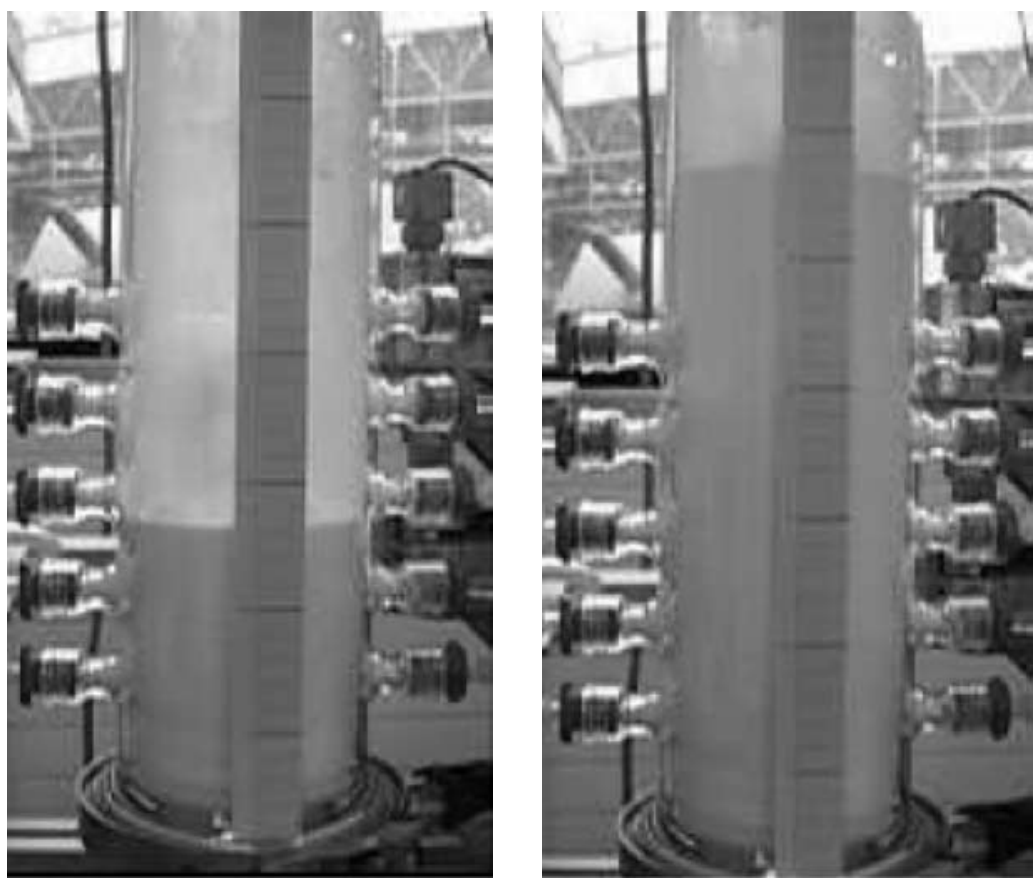

Fig. 9 Bed expansion of glass powder containing 1\% w/w Aerosil ${ }^{\circledR} 812 \mathrm{~S}$.

pansion of the bed was obtained $\left(\mathrm{H} / \mathrm{H}_{0}=2-2.5\right)$ when using Aerosil R812S as the additive (Fig. 9).

\subsection{Influence of fluidisation additive rate}

The additive rate is an important factor which influences the number of inserting particles. For example, during the investigation of flow properties of powder paints, Conesa et al. ${ }^{11)}$ reported that an optimal percentage of fluidisation additive exists beyond which the fluidisation is no longer enhanced or, in some cases, deteriorates. This optimal amount of additive depends on the physical properties of the original powder, the surface properties of both host and guest particles and the interactions between them, as well as the environmental conditions (temperature and humidity), process type and process-related variables.

The influence of the additive rate was investigated using batches formulated with the most effective glidant, i.e. Aerosil R812S, in different percentages (0.1, $0.2,0.3,0.4,0.5$ and $1 \% \mathrm{w} / \mathrm{w})$. Corresponding fluidisation curves are presented in Fig. 10. As can be seen, continuous improvement of $F Q$ is obtained when the percentage of Aerosil increases up to $0.5 \%$. Beyond this value, no significant improvement of fluidisation is observed. 


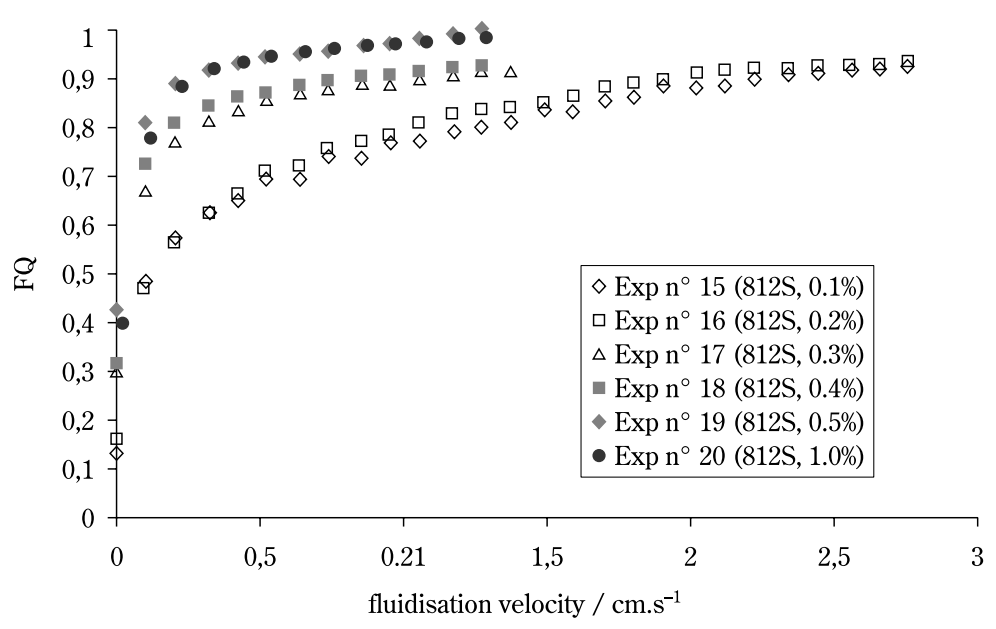

Fig. 10 Effect of the mass ratio of Aerosil ${ }^{\circledR} 812 \mathrm{~S}$ on fluidisation behaviour of the glass powder.

\section{Conclusions}

The fluidisation behaviour of a class $C$ glass powder was investigated. A fully automated experimental set-up was used to measure the fluidisation criteria: minimum fluidisation velocity, fluidisation quality, fluidisation index, and dynamic diameter of agglomerates.

The results showed that the introduction of easyto-fluidise particles to fresh powder does not allow its fluidisation. However, the fluidisation was achieved using an agitation system but the agitation velocity had no significant effect on fluidisation ability.

The most remarkable effects were obtained when using flow conditioners. In particular, adding adequate amounts ( 0.5 to $1 \%$ ) of a hydrophobic glidant (Aerosil R812S) led to a marked improvement of the fluidisation behaviour of glass powder so that it can be fluidised without any mechanical aid.

According to this study, it can be postulated that the effectiveness of glidants depends on two main parameters, namely the size of non-dispersive (inserting) aggregates and the hydrophobic extent of products. The size of inserting guest particles affects the gap between host particles and diminishes the attractive forces exerted between them. This conclusion was verified using both hydrophilic and hydrophobic glidants. As for the hydrophobicity of additives, this parameter doubly affects their effectiveness. Firstly, it plays a role on the dispersion of additives over the surface of host particles. A hydrophobic additive has more ease to spread over a hydrophilic support and vice versa. Secondly, van der Waals forces between two objects of opposite (hydrophobic/hydrophilic) natures are lower than two objects of similar nature.
These considerations indicate that counteracting hydrophobic properties are needed to obtain the most pronounced improvement in powder flowability. More investigation are, however, needed to describe more precisely the exact role of the hydrophobic/ hydrophilic nature of both support and additive powders.

\section{Notations}

$d_{a} \quad$ dynamic agglomerate diameter, [m]

$d_{p} \quad$ particle diameter, [m]

FI fluidisation index, [-]

$F Q$ fluidisation quality, [-]

$g \quad$ gravity acceleration, $\left[\mathrm{m} \cdot \mathrm{s}^{-2}\right]$

$H$ bed height, [m]

$M \quad$ mass of powder, [kg]

$\triangle P \quad$ pressure drop, $\left[\mathrm{kg} \cdot \mathrm{m} \cdot \mathrm{s}^{-1}\right]$

$S \quad$ cross-sectional area of the bed, $\left[\mathrm{m}^{2}\right]$

$U \quad$ superficial air velocity, $\left[\mathrm{m} \cdot \mathrm{s}^{-1}\right.$ ]

$U_{m f} \quad$ minimum fluidisation velocity, $\left[\mathrm{m} \cdot \mathrm{s}^{-1}\right]$

$\mu \quad$ viscosity, $\left[\mathrm{kg} \cdot \mathrm{m}^{-1} \cdot \mathrm{s}^{-1}\right]$

$\rho \quad$ mass density, $\left[\mathrm{kg} \cdot \mathrm{m}^{-3}\right]$

Subscripts:

Corr: correlation

Exp experimental

g gas

a aggregate

p particle

0 initial

\section{References}

1) Hémati M., Cherif R., Saleh K. and Pont V.: Fluidised- 
ged coating and granulation : influence of processrelated variables and physico-chemical properties

po won growth kinetics, Powder Technology, 130 (2003) 18-34.

2) Saleh K., Chérif R. \& Hémati M.: An experimental study of fluidized-bed coating: Influence of operating conditions on growth rate and mechanism, Journal of Advanced Powder Technology, Volume 10, No. 3, 255-278.

3) Geldart D.: Types of Gas Fluidisation, Powder Technology, 7 (1973) 285-292.

4) Visser J.: Van der Waals and the other cohesive forces affecting powder fluidisation, Powder Technology, 58 (1989) 1-10.

5) Lauga C., Chaouki J., Klvana D. and Chavarie C.: Improvement of the fluidisability of $\mathrm{Ni} / \mathrm{SiO}_{2}$ aerogels by reducing interparticle forces, Powder Technology 65 (1991) 461-468.

6) Yang W-C.: Fluidization of fine cohesive powders and nanoparticles - A review, J. Chin. Inst. Chem. Engrs
Vol. 36, n 1 (2005), 1-15.

7) Seville J.P.K, Willett C.D. and Knight P.C., Interparticle forces in fluidisation: a review, Powder Technology 113 (2000) 261-268.

8) Rumpf H.: Die Wissenschaft des Agglomerierens, Chemie-Ingenieur-Technik 46 (1) (1974) 1-11.

9) Meyer K. and Zimmermann I.: Effect of glidants in binary powder mixtures, Powder Technology 139 (2004) 40-54.

10) Thonglimp V., Hiquily N. and Laguerie C.: Vitesse minimale de fluidisation et expansion des couches de mélanges de particules solides fluidisées par un gaz, Powder Technology, 39 (1984) 223-239.

11) Conesa C., Saleh K., Thomas A., Guigon P., Guillot N.: Characterisation of Flow Properties of Powder Coatings Used in the Automotive Industry, KONA, 22 (2004), 94-106.

12) Kunii D. and Levenspiel O.: Fluidization Engineering, $2^{\text {nd }}$ Edition (1991), Butterworth-Heinemann, ISBN 0-409-90233-0. 


\section{Author's short biography}

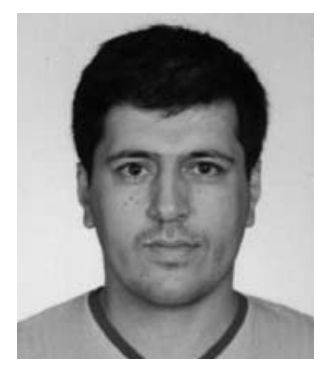

\section{Khashayar Saleh}

Khashayar SALEH received a B.S. degree in Chemical Engineering from Sharif (Aryamehr) university of technology (Tehran/Iran) in 1992. He prepared a $\mathrm{PhD}$ thesis on the coating of fine powders in the Chemical Engineering Laboratory of Toulouse and obtained his doctor's degree in 1998 from Institut National Polytechnique de Toulouse (France). Dr Saleh is currently associate professor in the chemical engineering department of the Compiègne University of Technology. His work is focused on powder technology including size enlargement technology and powder's characterisation methods.

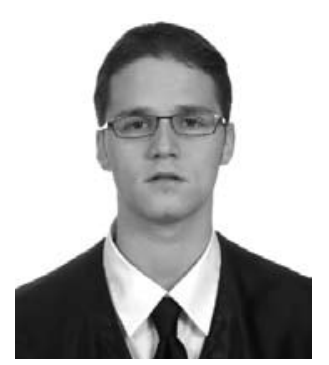

\section{Xavier BERNAT CAMÍ}

Xavier BERNAT CAMÍ is a Chemical Engineer from Rovira i Virgili University (Tarragona, Spain). He obtained a research Master in the field of Mass and Energy Transformation Processes from Compiègne University of Technology (Compiègne, France) in 2005. The research project of the Master was focused on the study of fluidisation ability of cohesive powders. Nowadays, he is a $\mathrm{PhD}$ student at Rovira i Virgili University (Tarragona, Spain). His current research is focused on wastewater treatment enhanced by membrane techniques. Concretely, he works with the recovery of homogeneous metallic catalysts, frequently used in advanced oxidation processes, with ultrafiltration ceramic membranes.

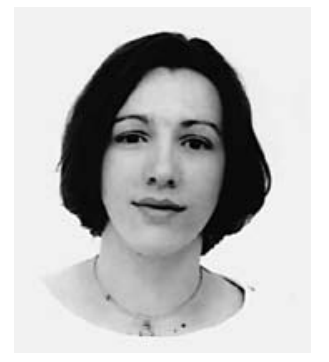

\section{Aline Thomas}

Aline THOMAS is a Ph.D student working in collaboration between the department of Chemical Engineering department of the Compiègne University of Technology (France) and the department of Materials and Painting Processes of the automotive company PSA Peugeot-Citroën. The subject of his research deals with the electrical behavior of powder coatings in order to characterize their electrostatic application in view of industrial applications.

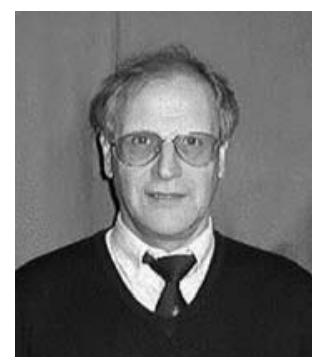

\section{Pierre Guigon}

Pierre Guigon is a Chemical Engineer from ENSIGC Toulouse (France 1971). Master of Engineering Science, UWO London Ontario, (Canada 1974), Docteur Ingénieur UTC Compiègne (France 1976), Docteur es Science UTC Compiègne (France 1978), Fellow of the Institution of Chemical Engineers. He is head of the Particle Technology Group at the Technical University of Compiègne. His research is in the field of particle suspensions (fluidization, pneumatic transport) and particle technology (communition and agglomeration). 